\title{
FUENTES PARA UNA HISTORIA DE LA MINERÍA BOLIVIANA DEL SIGLO XIX
}

\author{
Gustavo Rodríguez Ostria*
}

D odría decirse — quizá con nostalgia - que hasta 1987, año de profundas económico, Bolivia fue un país minero. No sólo por la secular importancia estratégica de los minerales dentro de su comercio internacional, sino principalmente por la presencia de una "cultura minera" que permeaba todo su andamiaje societal. Esto último es particularmente notorio en el caso de la arena sindical, donde pese a su escaso número "el proletariado del subsuelo" se constituyó desde los años cuarenta de esta centuria virtualmente en el locus, el 'eje articulador de las demandas de las clases subalternas. Y aunque se lo ha venido a denominar como la "centralidad minera", se desmoronó estrepitosamente cuando la crisis internacional del estaño (1985-1987) dio pie a que cerca del $80 \%$ de los radicalizados trabajadores de las empresas nacionalizadas, las más grandes del país, fueran despedidos. La dispersión de la comunidad minera, su inserción fragmentaria en otras actividades económicas y en un entorno cultural diferente, opacó toda una legendaria tradición que con fuego había impreso sus huellas en la historia contemporánea de Bolivia.

Estas reflexiones son importantes para comprender la significativa contradicción entre el medular papel jugado por la minería y su entorno social, y el escaso conocimiento sobre su comportamiento histórico y estructural. Pese a su importancia, la minería boliviana contemporánea fue escasamente revelada por científicos sociales e historiadores (si tal distinción es válida). En rigor de verdad, el reconocimiento que de ella se tiene nacía mucho más de la fuerza con la que sus agentes sociales impactaban en la sociedad civil, que de una explotación académica detenida.

* Gustavo Rodríguez Ostria, maestro en Historia Andina, catedrático de Historia Social Boliviana en la Escuela de Sociología de la Universidad Mayor de San Simón, Cochabamba, Bolivia. 
Al revisar el panorama historiográfico boliviano, no debería entonces extrañarnos que encontremos escasísimas obras capitales en relación con la minería, principalmente sobre el periodo republicano, y que ni siquiera pueda hablarse de una continua preocupación por su devenir. En efecto, ha pasado más de una década desde que Antonio Mitre ${ }^{1}$ publicara en Lima Los patriarcas de la plata, una versión ligeramente corregida de su tesis de doctorado, la más completa obra hasta hoy conocida en torno a minas y mineros en el siglo XIX. Fuera de ella, únicamente existen algunos trabajos de menor envergadura que, hay que reconocerlo, aun cuando en algunos puntos son más audaces y sugerentes que lo dicho por este autor, no alcanzan a dar cuenta plena del abigarrado panorama minero decimonónico.

Mitre se propuso "mostrar la génesis, evolución y crisis de la oligarquía minera de la plata en el siglo XIX, explicando las bases económicas de su poder". En este inédito empeño las contribuciones de Mitre fueron enormes, puesto que por primera vez mostró los problemas del funcionamiento minero, deteniéndose en considerar cómo la nueva elite minera que debutó en Bolivia hacia 1850, viniendo de la agricultura y el comercio, encaró sus problemas de capitalización y tecnología que la acosaban desde los inicios de la era republicana (1825). Désde 1873 hasta 1885 esta nueva fuerza logró movilizar tanto capital extranjero, chileno casi en su totalidad, como nacional para tecnificar la fase de extracción, refinado de mineral y sistema de transporte. Luego de una bullente fase, que duró hasta las postrimerías de la anterior centuria, la minería de la plata se colapsó cuando su precio se derrumbó en el mercado mundial. Casi al instante, para suerte de la economía boliviana, fue sustituida por el estaño.

Mitre, por otra parte, siguiendo los novedosos lineamientos de Carlos Sempat Assadourian en torno al funcionamiento del "espacio peruano", estableció los impactos que el desarrollo de esta actividad ocasionó en el funcionamiento de la trama mercantil y el mercado interior de raigambre colonial. Para él, el boom minero argentífero de fines del siglo pasado no dinamizó el mercado interior boliviano, como era norma durante la era colonial, ${ }^{4}$ y por el contrario propició su desmembramiento en beneficio de la producción importada, principalmente chilena.

Pese a estas importantes contribuciones que revolucionaron la historio-

${ }^{1}$ Antonio Mitre, Los patriarcas de la plata. Estructura socioeconómica de la minería boliviana en el siglo XrX, IEP, Lima, 1981.

2 Antonio Mitre, "Economic and social estructure of silver mining in XIX century Bolivia", tesis de doctorado, Columbia University, 1977.

${ }^{3}$ Ibid., pp. 17-18.

${ }^{4}$ Véase Carlos Sempat Assadourian, "Integración y desintegración regional en el espacio colonial: un enfoque histórico", Revista Latinoamericana de Estudios Urbano-Regionales, EURE, Santiago de Chile, 1972. 
grafía bolivianista, tres notorias ausencias pueden reprocharse al autor de Los patriarcas. Por un lado, su inocultable sesgo en la Compañía Minera de Huanchaca, una dinámica empresa formada con capital chileno y boliviano, responsable de más de $50 \%$ de la producción de plata. Inclinación que lo llevó a descuidar a las casi dos docenas de pequeñas y medianas minas organizadas a partir de 1885 por capital exclusivamente nacional. Una comparación entre ambas racionalidades y modalidades productivas hubiera sido más que provechosa para tener un panorama completo de la estructura minera. Por otro lado, Mitre, salvo algunas indicaciones puntuales, no toma en cuenta las visicitudes e importancia de un sector paralelo a la producción "oficial" de plata, como fue el kajcheo. Originado en el siglo XVII, y emparentado con la huachaca peruana o el partido mexicano, les corresponde a los kajchas cumplir, aunque con altibajos, un papel de primer orden en las actividades mineras republicanas, tanto que en el lapso comprendido entre 1825-1950 fueron responsables de la producción de aproximadamente $35 \%$ de la plata extraída del Cerro Rico de Potosí. En esos mismos años, los kajchas dominaban diversos asientos minerales, como Porco, Colquechaca y Oruro, los que al filo del siglo XIX serían la base de la renovación minera en Bolivia. Last but not least, en Los patriarcas el problemático funcionamiento del mercado de trabajo minero y la formación de una cultura minera industrial están notablemente ausentes. Este punto es indudablemente el más débil de todo el libro, dejando al lector con un franco sabor de insatisfacción.

¿Hacia dónde han ido posteriormente las investigaciones sobre la minería boliviana decimonónica? Lamentablemente los logros son notoriamente escasos. Es de reconocer que la historiografía boliviana, finalmente hija de su tiempo, ha sufrido el impacto de la crisis minera aludida precedentemente. La opacidad actual de los trabajadores mineros y el surgimiento de otros movimientos sociales como el indigenismo, han contribuido a que su atención se desvíe preferentemente hacia las conflictivas y cambiantes relaciones entre el naciente Estado criollo posindependentista y las territorialmente importantes comunidades indígenas. Hoy, al menos en lo que se refiere al periodo republicano temprano, hay escaso interés por el tema minero. Y no parece que en un plazo corto vaya a renovárselo.

Quizá seamos la excepción. Desde 1985 hemos venido publicando distintos trabajos sobre la condición de los trabajadores mineros en el siglo XIX. Para ello partimos del cuadro general de la economía minera descrito por Mitre, pero, como veremos luego, incidimos en lo que consideramos sus vacíos más notables. 


\section{LOS KAJCHAS: LA OTRA MINERÍA}

Como ya aludimos en el análisis de Mitre, toda la abigarrada actividad desarrollada por pequeños mineros y trapicheros indios y mestizos, cobijados bajo el denominativo de kajchas, quedó lamentablemente en la sombra. Es posible que ello se debiera en buena parte a la documentación que utilizó y a las preguntas que dibujó para interrogarla. Él trabajó fundamentalmente con las Memorias que los distintos directorios de las compañías mineras expedían anualmente a sus socios, y de modo más secundario con la prensa de la época. Es claro que en las primeras fuentes documentales esta actividad popular simplemente no aparece para nada. Por dos razones no necesariamente obvias. La primera, en virtud de que las empresas mineras se generalizaron entre los años setenta y ochenta, cuando el auge del kajcheo había pasado. En segundo término, en virtud de que las Memorias incidían fundamentalmente en la dinámica interna, tecnológica, administrativa y laboral de cada empresa, y por consiguiente no daban una visión de conjunto de la economía minera y sus diversos problemas.

Nuestras investigaciones nos permitieron en cambio rescatar la dinámica de esa minería paralela (hoy se la llamaría abusivamente informal). ${ }^{5}$ Constatamos así que el kajcheo colonial, que por entonces constituía una actividad que permitía a los trabajadores y pobladores de la ciudad apoderarse libremente entre el sábado en la noche y la madrugada del lunes de piezas de mineral (corpas), se había transformado en las primeras décadas de la era republicana en un laboreo al partir (mediería). ${ }^{6}$ Los kajchas, generalmente comandados por un barretero, aportaban su fuerza de trabajo, velas, pólvora y herramientas, mientras el propietario "ponía" la mina en reciprocidad. Posteriormente se repartía el mineral extraído, el 50\% para cada "socio". Los kajchas estaban fuertemente articulados dentro de una "compleja liga" que abarcaba a propietarios de pequeños trapiches y rescatistas de mineral, que generalmente les adelantaban o prestaban dinero, recibiendo a cambio un suculento interés y la opción preferente de adquirir el mineral de los kajchas, generalmente a precios inferiores al vigente en el mercado.

Para seguir las pistas de los decisivos kajchas, convenía no sólo plantearse nuevos problemas sino, en consonancia, también desenterrar fuentes documentales distintas a las utilizadas por Mitre. En el Archivo Nacional de Bolivia (ANB), ubicado en la ciudad de Sucre, capital de Botivia, se conserva afortunadamente la correspondencia de los ministros de Hacienda e Interior

${ }^{5}$ Gustavo Rodríguez Ostria, "Kajchas, trapicheros y ladrones de mineral en Bolivia (18241900)", Siglo XIX. Revista de Historia, Monterrey, año IV, núm. 8, pp. 125-139.

${ }^{6}$ Para los kajchas en el periodo colonial véase Enrique Tandeter, Coacción y mercado. La minería de la plata en el Potosí colonial. 1629-1826, CBC, Cusco, 1992 (en especial el capítulo II). 
con las prefecturas (gobernaciones) y subprefecturas. Esta abundante documentación, que está catalogada cronológicamente, circunscripción geográfica y, para algunos años, por grandes temas (por ejemplo, Tribunal de Minería), constituye el fondo documental más rico para la historia de la minería boliviana, principalmente hasta los años ochenta de la centuria pasada. Mitre, sin embargo, no exploró este emporio. Hay que convenir, por otra parte, que pese a su cuidado y a la catalogación avanzada, no es fácil trabajar en él. Los documentos oficiales, $y$ por consiguiente las temáticas, vienen generalmente mezcladas. Por tanto, en el mismo "legajo" (paquete) se combinan problemas tan diversos como revueltas militares, estructuras impositivas e inspecciones mineras. En ese contexto, para encontrar sabrosos frutos y alcanzar un panorama completo de la esfera minera, es absolutamente imprescindible revisar todos y cada uno de los legajos correspondientes al departamento (provincia) de Potosí, centro de la minería republicana. La recompensa del esfuerzo es, empero, enorme. No era infrecuente que el Estado boliviano, preocupado por la desorganización y la caída de la producción minera que fructificó en la primera mitad del siglo XIX, destacara sendas comisiones para visitar las minas y elevar informes al ejecutivo; inspectores y entendidos visitaban cada mina a la que escrutaban detalladamente. Pero también, y esto es lo que nos interesa, se preocupaban aunque con menor énfasis por la otra minería que estaba en manos de kajchas y trapicheros. Algunas de estas pormenorizadas visitas fueron publicadas en folletos o en la prensa de la época a principios de los años treinta y cincuenta, otras y muy importantes permanecieron en cambio en la oscuridad.

Documentación de este tipo, complementada adecuadamente con las crónicas que con cierta frecuencia aparecían en los periódicos, principalmente cuando autoridades y empresarios mineros se quejaban de las prácticas poco convencionales de los núcleos mineros populares afiliados al kajcheo y los trapiches, nos entregan un cuadro vivo y rico del espectro productivo de la minería popular. Lamentablemente no son suficientes para desentrañarla plenamente, pues existen todavía vacíos, ya que en muchos casos son miradas "oficiales" que escrutan espasmódicamente esta actividad con desconfianza para sancionarla antes que comprenderla. La perspectiva desde dentro, respetando la lógica cultural y productiva de estos actores productivos, es francamente inexistente. Incluso con una lectura oblicua no es siempre posible saber quiénes eran propiamente los kajchas y quiénes los trapicheros. Por suerte, algunas pistas pueden recogerse de los Protocolos Notariales depositados en el Archivo de la Casa de la Moneda (Potosí). De vez en cuando aparecen allí las transacciones que realizaban los trapicheros y los kajchas. Gracias a ellos sabemos que una compleja gama de hombres y mujeres, indios y mestizos, transitaba con fortuna en esta ignorada minería.

En cambio, afortunadamente es mucho más fácil seguir en la larga dura- 
ción la contribución de kajchas y trapicheros al volumen de la producción argentífera boliviana. Hasta 1872, como una controvertida herencia colonial, funcionaron los Bancos de Rescate, síntesis del monopolio estatal sobre la comercialización de la plata. Merced a ello, su documentación - principalmente los libros en los que se asentaban sus transacciones, depositados en el Archivo de la Casa de la Moneda, y los meticulosos resúmenes que de ellos se conservan en la colección Ruck del ANB - nos facilita desentrañar este derrotero y su gravitante importancia económica para la supervivencia de la minería boliviana decimonónica.

\section{Una cultura en transición}

La literatura latinoamericana más reciente, al examinar el proceso de proletarización, presta ahora mucha más atención a los aspectos gestuales y simbólicos que lo acompañan que a los meramente infraestructurales. Así, la formación del mercado de trabajo se acompaña preferentemente con el estudio de las sanciones, normas disciplinarias y actitudes psicológicas que estructuran una cultura obrera. ${ }^{7}$

En el caso boliviano, empero, por distintas razones que no vamos a enumerar, tal vuelco no se ha dado decisivamente. Ya dijimos que la evolución de la mano de obra constituía el punto más flaco en el trabajo de Mitre, atrapado en la tentación de ofrecer una visión estadística en una sociedad escasamente cuantificable. Estudios documentados, como el realizado por Heraclio Bonilla y Carmen Zalazar, ${ }^{8}$ basados en cuantificación de las fichas de los trabajadores mineros peruanos, simplemente son impensables para la Bolivia del XIX. Falta el sustento de los datos para concretarlos. Inicialmente, su ausencia es explicable en virtud de la desorganización de las propias compañías y de su escasa sistematización administrativa; las empresas bolivianas apenas llevaban un registro burdo de sus trabajadores. Posteriormente, a fines de siglo, pese a que poseían ya un registro contable y administrativo "científico", lamentablemente no conservaron esta documentación en los archivos. Si a ello se agrega que en la centuria anterior Bolivia apenas contó con sólo dos censos, de calidad dudosa, y donde la información está demasiado agregada, concluimos que estudiar el funcionamiento del mercado de trabajo minero no es una tarea precisamente fácil. Quizá la única aproximación realmente lateral consista en usar la metodología empleada por Carlos Contreras, que se ba-

\footnotetext{
${ }^{7}$ Véase José Sergio Lete Lópes, Cultura e identidad operaria, UFR, Río, 1991.

${ }^{8}$ Heraclio Bonilla y Carmen Zalazar, "La formación del mercado laboral para el sector minero (la experiencia de Huancavelica, Perú 1950-1978)", Economía, vol. vi, núms. 11-12, PUCP, pp. 9-45.
} 
sa en datos parroquiales como partidas de nacimiento, bautizo y matrimonio. ${ }^{9}$ Contreras pudo establecer así que la oferta de trabajadores fluctuaba en relación con los ciclos agrícolas y las festividades civiles y religiosas. Reconocemos que no hemos intentado esta vía desalentados por el costo de afrontar la dispersión de estas fuentes que, por otra parte, se hallan muy mal conservadas y sin catalogación en manos de la Iglesia y las autoridades locales.

Mas si la historia cuantitativa de la fuerza de trabajo minera boliviana halla sus propios límites descriptivos, afortunadamente no sucede lo propio con la historia social (usando el término en sentido amplio). Tocando los hilos adecuados en la documentación anteriormente mencionada, perteneciente al ANB, es posible tejer un panorama bastante completo de la cultura íntima de los trabajadores mineros y sus mutaciones en la primera mitad del siglo XIX. ${ }^{10}$ Esta posibilidad es atractiva: los reclamos por indisciplina, borrachera y hurto, peculiares de un mundo todavía preindustrial gustoso del ocio y del "san lunes", brotan incontenibles de las inumerables quejas de los propietarios de minas y de los funcionarios públicos, así como de la descripción sustantiva que las empresas hacen en la prensa local sobre las costumbres mineras, y que posee un colorido y una riqueza testimonial enorme.

Como sea, al promediar el siglo y a medida que las empresas mineras crecían y se afianzaban, la documentación privada producida por ellas fue sustituyendo paulatinamente a la estatal; las Memorias de las compañías mineras, que habitualmente incorporan los nuevos reglamentos y medidas disciplinarias así como una evaluación de su cumplimiento, constituyen otra fuente destacable en este terreno. En la Biblioteca Nacional de Bolivia (BNBSucre), anexa al Archivo Nacional, existe afortunadamente una numerosa colección de ellas que prácticamente abarca, año por año, a casi todas las compañías que operaron en el país en las dos últimas décadas del siglo precedente. Por supuesto que las Memorias pueden ser usadas ventajosamente para algo más que para explorar los cambios en la cultura obrera; son, por otra parte, invalorables fuentes sobre la tecnología, los volúmenes de producción, los problemas administrativos, etcétera.

Asimismo, como documentos destinados a informar a los socios de sus logros y tribulaciones, las Memorias tienen un comprensible sesgo en la mirada patronal. La "otra" historia, esta vez la de las clases subalternas, no tiene pues testimonios directos, lo que obliga al historiador que quiera reconstruirla a una lectura oblicua de las fuentes empresariales.

En este último terreno, una documentación generosa y determinante es la perteneciente al importante empresario minero Gregorio Pacheco. Sus varios

\footnotetext{
${ }^{9}$ Carlos Contreras, Mineros y campesinos en los Andes, IEP, Lima, 1988.

${ }^{10}$ Gustavo Rodríguez Ostria, El socavón y el sindicato. Ensayos históricos sobre los trabajadores mineros. Siglos XrX-XX, LLDIS, La Paz, 1991 (especialmente el capítulo 1).
} 
"copiadores" de correspondencia, conservados en la Biblioteca de la Universidad Mayor de San Andrés (La Paz), nos proporcionan meticulosa y casi diariamente la visión, los logros y las visicitudes de este modernizador en el largo periodo de 1870 a 1895 . Cabe advertir que la documentación, que no ha sido trabajada a profundidad por los historiadores, está circunscrita a la mina Guadalupe, la segunda productora de plata en Bolivia en ese lapso.

La práctica de los "copiadores", por los pequeños y fragmentarios rastros que otros mineros importantes han dejado, debió estar extendida entre los empresarios de la plata. Por desgracia, nos ha llegado únicamente la de $\mathrm{Pa}$ checo. El fuego, el maltrato y la desidia oficial han contribuido a que el tiempo las carcoma.

\section{CONCLUSIÓN}

En contraste con la era colonial, los trabajos a profundidad sobre la historia minera boliviana del siglo XIX son escasos. Pasa más de una década de la publicación de la obra capital de Antonio Mitre. Las pocas investigaciones que han tocado este periodo tratan más bien de los trabajadores que del régimen de funcionamiento de las empresas mineras o de la macroeconomía minera. Si bien durante la segunda mitad del siglo abundan las fuentes oficiales, para la segunda mitad son más importantes las privadas, que se originan en las diferentes compañías mineras que contribuyeron al renacimiento argentífero en los años ochenta. Esta documentación se concentra básicamente en las Memorias anuales de cada empresa, y en mucho menor grado en fuentes inéditas como registros de personal, libros de contabilidad, copiadores de correspondencia, que prácticamente no se conservan o que no son accesibles. Bajo estas circunstancias, algunos problemas como la estructura del mercado de trabajo o la perspectiva de los laboreros mineros y pequeños productores sólo puede alcanzarse fragmentariamente. 